\title{
COMPARAÇÃO DE REVESTIMENTO DURO EM FACAS PICADORAS DE CANA- DE-AÇÚCAR NO SETOR SUCROALCOOLEIRO COM ARAME TUBULAR E ELETRODO REVESTIDO
}

\author{
COMPARISON OF HARD SURFACE ON SUGAR CANE CHOPPING KNIVES IN THE \\ SUGAR-ALCOHOL SECTOR WITH FLUX CORED ARC WELDING AND SHIELDED \\ METAL ARC WELDING
}

\author{
José Filho Santos de Andrade \\ Filipe Rodrigo Mendes ${ }^{\text {II }}$ \\ Antônio Carlos Muniz Ventura Junior ${ }^{\mathrm{III}}$
}

\begin{abstract}
RESUMO
A alta produtividade no setor sucroalcooleiro no Brasil, a manutenção dos seus equipamentos é devidamente necessária, em função ao grande desgaste no período de safra. Um desses equipamentos é a faca picadora de cana de açúcar, que são os primeiros equipamentos a entrar em contato com a cana de açúcar, que vem da colheita junto com várias impurezas que causam desgaste neste equipamento. Com isso é necessário realizar um revestimento para diminuir esse desgaste. Neste artigo foi apresentado dois tipos de revestimento por solda dura para esse equipamento, o processo com eletrodo revestido ESSEN CCR 65, e o processo com arame tubular KST TUB M 630 OA ambos com Ferro (Fe), Cromo (Cr), e Carbono (C) e outros elementos de liga presentes em sua composição. Foram realizados ensaios de dureza, desgaste, e microestrutura nos corpos de prova. O consumível ESSEN CCR 65 obteve o melhor resultado na aplicação do revestimento para desgaste.
\end{abstract}

Palavras-chave: Revestimento Duro. Arame Tubular. Eletrodo Revestido. Facas Picadoras de Cana de Açúcar.

\begin{abstract}
The high productivity in the sugar alcohol sector in Brazil, the maintenance of its equipment is properly necessary, in function to the great wear in the period of harvest. One of these equipment is the sugarcane chopper blade, which are the first equipment to be in contact with the sugarcane, that comes from the harvest full of impurities, these impurities cause a great wear on this equipment. So, it is necessary to make a coating to decrease this wear. On this article two different types of coating by hard welding for this equipment were presented, the process with shielded electrode ESSEN CCR 65, and the process with tubular wire KST TUB M 630 OA both with Iron (Fe), Chromium (Cr), e Carbon (C) and other alloy elements being on its composition. Tests of hardness, wear and microstructure in the specimens and it was found that the process of welding with shielded electrode occurred with less wear than the process with tubular wire. The ESSEN CCR65 consumable obtained the best result in the application of the wear coating.
\end{abstract}

\footnotetext{
IEstudante do Curso Superior de Tecnologia Mecânica. Fatec Sertãozinho. E-mail: joseandrade3190@gmail.com IIEstudante do Curso Superior de Tecnologia Mecânica. Fatec Sertãozinho. E-mail: filipemendes016@outlook.com III Prof. Me da Fatec Sertãozinho. E-mail: antonio.ventura@fatec.sp.gov.br
} 


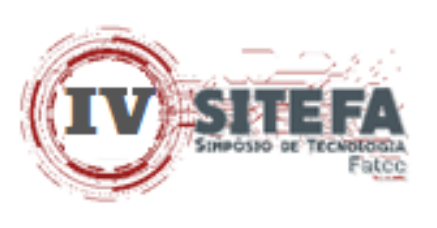

Keywords: Hard Coating. Tubular Wire. Shielded Electrode. Sugar Cane Chopping Knives.

Data de submissão do artigo: 29/05/2021.

Data de aprovação do artigo: 01/07/2021.

DOI: $10.33635 /$ sitefa.v4i1.155

\section{INTRODUÇÃO}

Neste trabalho foi realizado com os processos de soldagem por arco elétrico Flux Cored Arc Welding (FCAW) e o Shielded Metal Arc Welding (SMAW) por serem empregados na manutenção e reparos para realizar a soldagem de revestimento superficial nas faces das facas picadoras de cana de açúcar.

De acordo com Lima (2012 apud HUTCHINGS, 1992) a soldagem por revestimento duro é um processo utilizado para aumentar a resistência ao desgaste de um equipamento com a finalidade de endurecer somente a sua superfície, mantendo a tenacidade do seu núcleo. Esse processo é muito utilizado nas indústrias sucroalcooleiras, mineradoras e petroleiras.

As facas picadoras de cana de açúcar são os primeiros equipamentos a entrar em contato com a cana de açúcar, preparando-as para a próxima etapa que é a extração de caldo. A cana de açúcar vem da colheita junto com várias impurezas como à areia, argila e pedras, causando um grande desgaste na sua superfície (LIMA et al., 2012).

Foram realizados ensaios de desgaste, dureza e microestrutura para definir qual dos dois processos atenderia melhor a resistência ao desgaste.

\section{SETOR SUCROALCOOLEIRO}

Na safra 2020/2021, “o Brasil produziu aproximadamente 597 milhões de toneladas de cana-de-açúcar, matéria-prima utilizada para produção de 38 milhões de toneladas de açúcar, 29 bilhões de litros de etanol e 27,5 TWh para a rede elétrica nacional" (ÚNICA, 2020, p. 02). O etanol de cana de açúcar é o biocombustível com menos taxa de carbono no mundo, com fonte limpa e renovável de energia sustentável em toda sua cadeia, gerando emprego e renda no campo. A bioeletricidade gerada pela cana de açúcar é a quarta fonte mais importante da matriz elétrica no Brasil. Dentre outros produtos como: etanol $2 \mathrm{~g}$, biogás, biometano, plástico e cosméticos (ÚNICA, 2020).

$\mathrm{Na}$ indústria sucroalcooleira ocorre muitos desgastes nos seus equipamentos de extração de caldo, necessitando realizar uma soldagem de manutenção, um desses processos é a soldagem de revestimento, que é uma soldagem preventiva, realizada nos picadores, desfibradores e moendas. O picador é composto por um ou dois conjuntos de facas que trabalham em rotação, numa velocidade de $60 \mathrm{~m} / \mathrm{s}$, picando a cana em pedaços pequenos preparando-as para a próxima etapa, onde ela é encaminhada para o desfibrador (LIMA et al., 2012).

\subsection{Aço ao Carbono ASTM A-36}

O aço carbono American Society for Testing and Materials (ASTM) A-36 é um aço muito utilizado, por vários segmentos nas indústrias de metalomecânica, pois ele apresenta uma ótima soldabilidade e resistência mecânica entre 400MPa e 550MPa (ASTM, 2021). Os perfis 


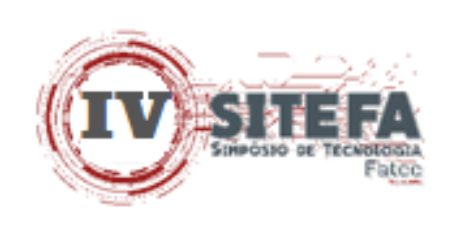

estruturais que são fabricados em chapas de aço, possuem uma resistência para aplicação em variados componentes estruturais, desde os mais comuns até os mais elaborados como, estruturas metálicas em geral, setor de ferrovias, máquinas, serralheria, passarelas, além de implementos agrícolas (ALLGAYER, 2017).

Existem diversos tipos de aços produzidos em uma vasta variedade de formas e tipos, tais como chapas, perfis, tubos e barras.

Os chamados aços estruturais possuem uma maior relevância pois apresentam uma média e alta resistência mecânica, dentre esses aços estruturais está o aço ASTM A-36 que atualmente é o mais empregado. Um ponto negativo deste aço é sua propensão de ferrugem, caso não houver um revestimento (ALLGAYER, 2017).

\subsection{Facas picadoras de cana de açúcar}

As facas picadoras são as primeiras a entrar com contato com a cana de açúcar durante a preparação da cana para extrair o caldo, elas têm a função de cortar e desfibrar as células da cana para maior extração da sacarose nas moendas. Para aumentar sua resistência ao desgaste ela é fabricada de material de baixo teor de carbono (ASTM A-36), e revestida por soldagem para melhorar o desgaste nas faces onde entra em contato direto com a cana. O desgaste dessas ferramentas é devido à alta velocidade de impacto com a cana, que vem junto com elementos grosseiros como a areia, pedaços de madeira, raízes, pedras de ferro que são coletados durante o processo de carregamento (LIMA et al., 2012).

As facas picadoras são constituídas por um conjunto de um ou dois jogos de facas (dois conjuntos em sequência) ela prepara a cana que será enviada ao desfibrilador. Esse é um equipamento de facas oscilantes, ele opera em uma velocidade que pode chegar até $60 \mathrm{~m} / \mathrm{s}$, sua função é aumentar a densidade da cana cortando em vários pequenos pedaços preparando para o trabalho do desfibrilador. Na Figura 1 mostra o detalhe de uma faca picadora com seu revestimento (LIMA; FERRARESI, 2006).

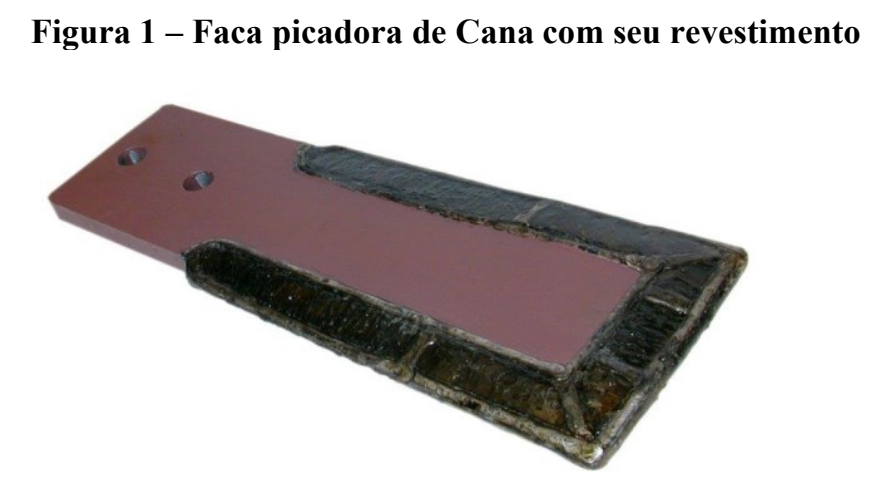

Fonte: Solbrinil (2020)

\subsection{Soldagem}

Grande número dos processos de união realizado nas indústrias, utilizam o termo soldagem. Porém a soldagem não é somente utilizada para unir materiais, ela também é utilizada para recuperar equipamentos desgastados pelo uso e, também, para revestir um determinado material para fins específico, como para garantir a resistência ao desgaste, utilizada para proteção da superfície (MARQUES; MODENESI; BRACARENSE, 2011). 


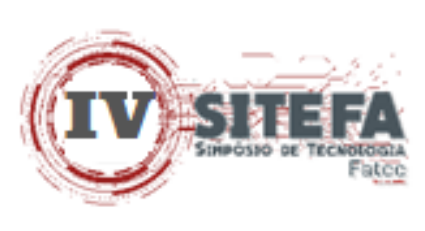

Embora a soldagem seja um processo recente com menos de 150 anos, a brasagem e a soldagem por forjamento têm sido realizadas desde épocas remotas e no Museu de Louvre em Paris existe um pingente de ouro fabricado na Pérsia por volta de $4000 \mathrm{AC}$, com indícios de soldagem (MODENESI; MARQUES; SANTOS, 2012).

De acordo com Marques, Modenesi e Bracarense (2011, p.18) "a soldagem é a união mais usado nas indústrias", com uma grande variabilidade de aplicação desde a indústria microeletrônica até a fabricação de grandes equipamentos e estruturas que chegam a pesar toneladas de peso.

\subsubsection{Soldagem de revestimento duro}

O revestimento duro trata-se de uma liga depositada na superfície de um material mole por soldagem, com o objetivo de aumentar a sua dureza e resistência ao desgaste mantendo a tenacidade do substrato no seu interior (LIMA et al., 2012).

\subsubsection{Soldagem com eletrodo revestido}

O processo de soldagem com eletrodo revestido é o mais amplamente utilizado. Possui a maior flexibilidade entre todos os processos de soldagem uma vez que a maioria dos metais pode ser unida ou revestida pela soldagem. Existe uma grande variedade de eletrodos revestidos, facilmente encontrados no mercado, cada eletrodo contendo no seu revestimento a capacidade de produzir os próprios gases de proteção dispensando o suprimento adicional de gases, necessário em outros processos de soldagem. Eletrodos revestidos podem ser usados em todas as posições (plana, vertical, horizontal, sobre cabeça), (FORTES, 2004). A soldagem realizada pelo eletrodo revestido acontece através do aquecimento do eletrodo e do metal de base, esse aquecimento é gerado através de um arco elétrico que funde o eletrodo no metal de base. O eletrodo é formado por uma vareta fundida ou trefilada denominada "alma", ela é o metal de adição que preenche a junta soldada e, também, a condutora da corrente elétrica. $\mathrm{O}$ revestimento do eletrodo é uma mistura de diferentes materiais que recobre a alma, ele tem a finalidade de estabilizar o arco elétrico, eliminar as impurezas ajustando a composição química da solda, durante a soldagem ele gera uma camada de gases para proteger a poça de fusão de contaminantes externos, e forma uma camada de escória por cima da solda (MARQUES; MODENESI; BRACARENSE, 2011).

\subsubsection{Soldagem com arame tubular}

O processo de soldagem com arames tubulares FCAW (Flux Cored Arc Welding) é, fundamentalmente, baseado nos mesmos princípios e equipamentos utilizados pelo processo semiautomático do arame sólido. Umas das principais diferenças entre ambos está na possibilidade de não usar gás de proteção devido ao fluxo no interior do arame tubular. Os processos estão relacionados à versatilidade, produtividade e integridade do metal depositado garantidas com arames tubulares. A alta produtividade é uma das grandes vantagens do processo de soldagem com arames tubulares e está associada, principalmente, as altas taxas de deposição obtidas nesse processo. (FORTES, 2004). 


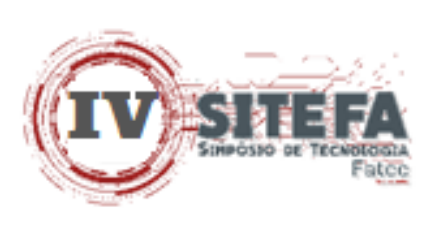

\subsection{Ensaios mecânicos}

Na montagem de estruturas mecânicas são usados os materiais metálicos e suas ligas, nesse caso é necessário conhecer as suas propriedades mecânicas, como dureza, resistência a tração e compressão, tenacidade à fratura e ao impacto, comportamento em fadiga e microestrutura. Essas propriedades definem qual a capacidade de cada material de resistir os esforços do projeto, tanto em altas temperaturas como em temperatura ambiente. Geralmente os ensaios mecânicos seguem os requisitos que estão estabelecidos nas normas internacionais e nacionais (MILAN et al., 2014).

\subsubsection{Ensaio de análise de microestrutura (ensaios metalográficos)}

A análise microestrutural consiste na caracterização do tipo, tamanho, forma $\mathrm{e}$ distribuição de fases, estruturas e impurezas presentes em um material com o uso de um microscópio. A análise de metalografia permite analisar e identificar as alterações na microestrutura do material, alterações decorrentes de tratamentos térmicos ou mecânicos, sua variação na composição química ou sua taxa de resfriamento. As etapas do ensaio metalográfico consiste na escolha e na preparação da amostra, ataque químico, observação microscópica e aquisição e análise de imagens (MILAN et al., 2014).

\subsubsection{Ensaio de Dureza}

O ensaio de dureza tem por finalidade obter a dureza na superfície revestida por soldagem em função da sua identação e por meio de tabelas, obter uma correlação aproximada entre os métodos de determinação de dureza para determinar materiais mais duros ou mais dúcteis por meio de consulta entre as escalas Brinell, Rockwell e Vickers e os valores de limite de resistência à tração (LUZ, 2017).

O ensaio de dureza é muito importante nas indústrias, serve para se obter um comparativo da resistência mecânica de um determinado material, avaliar resultados de tratamentos térmicos, entre outras. Este ensaio é considerado um ensaio não destrutivo, ele deixa uma pequena marca estampada na peça, porém não compromete em nada seu desempenho técnico. (CALLISTER JUNIOR, 2000).

\subsubsection{Abrasômetro tipo roda de borracha}

O desgaste abrasivo tem sido foco de importância na indústria mundial. Estima-se que $50 \%$ de todos os problemas relacionados a desgaste na indústria são devido à abrasão, e com isso, muitos trabalhos de laboratório têm examinado e procurado racionalizar o comportamento em desgaste abrasivo de uma grande gama de materiais (LUZZI; OKURA, 2012). Com isso, muitos modelos de ensaios vêm se desenvolvendo. Os modelos de ensaios podem ser divididos entre aqueles que foca que o abrasivo se mova solto, enquanto ele passa sobre o corpo de prova (abrasão a três corpos), também existe aquele método no qual o abrasivo está engastado, enquanto ele vai se deslocando sobre o corpo de prova. A norma mais comum utilizada no tipo de abrasão a três corpos, é a norma Standard Test Method for Measuring Abrasion Using the Dry Sand/Rubber Wheel Apparatus (ASTM G65 - 16e1), conhecido como ensaio de roda de borracha com areia seca (LUZZI; OKURA, 2012). 


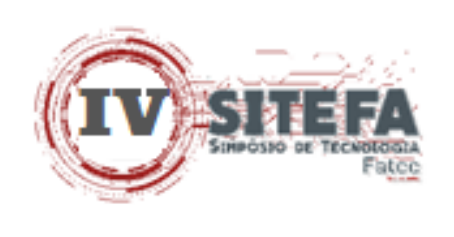

\section{MATERIAIS E MÉTODOS}

Para o desenvolvimento desse projeto foram confeccionados seis corpos de prova para o ensaio de dureza e desgaste, sendo três revestidos com o processo de soldagem FCAW (arame tubular), e três revestidos com o processo de soldagem SMAW (eletrodo revestido). Os corpos de prova foram identificados como: CP 01, CP 02, CP 03 para os revestidos com o processo FCAW, e CP 04, CP 05, CP 06 para os revestidos com o processo SMAW, com as suas dimensões $25 \mathrm{~mm}$ de largura $\mathrm{x} 60 \mathrm{~mm}$ de comprimento e $12 \mathrm{~mm}$ de espessura.

Para o ensaio de metalografia foi confeccionado dois corpos de prova revestidos com o processo de soldagem FCAW, e dois corpos de prova revestidos com o processo de soldagem SMAW. Todos os ensaios foram realizados no laboratório da FATEC de Sertãozinho.

\subsection{Material de Base}

O material de estudo para aplicação da solda de revestimento é um aço ASTM A-36, típico de facas picadoras. Para este estudo, utilizamos uma amostra da peça. A Tabela 1 apresenta a composição química do material.

Tabela 1- Composição química do aço ASTM A-36

\begin{tabular}{ccccc}
\hline $\begin{array}{c}\text { Carbono } \\
\text { máx. }\end{array}$ & $\begin{array}{c}\text { Manganês } \\
\text { máx }\end{array}$ & $\begin{array}{c}\text { Silício } \\
\text { máx }\end{array}$ & $\begin{array}{c}\text { Fósforo } \\
\text { máx. }\end{array}$ & $\begin{array}{c}\text { Enxofre } \\
\text { máx. }\end{array}$ \\
\hline $0,26 \%$ & $1,35 \%$ & $0,4 \%$ & $0,04 \%$ & $0,05 \%$ \\
\hline
\end{tabular}

Fonte: Norma ASTM A-36, 2008

\subsection{Eletrodo revestido}

O eletrodo revestido utilizado no revestimento superficial dos corpos de prova foi o ESSEN CCR 65, diâmetro 4 mm, do fornecedor Uniweld, e sua composição está mostrado na Tabela 2.

Tabela 2- Composição do eletrodo ESSEN CCR 65

\begin{tabular}{cccccccc}
\hline $\mathbf{C}$ & $\mathbf{S i}$ & $\mathbf{M n}$ & $\mathbf{C r}$ & $\mathbf{W}$ & $\mathbf{N b}$ & $\mathbf{V}$ & Mo \\
\hline $3,00 \mathrm{a}$ & $1,50 \mathrm{a}$ & $0,50 \mathrm{a}$ & $18,00 \mathrm{a}$ & $1,00 \mathrm{a}$ & $5,00 \mathrm{a}$ & $1,00 \mathrm{a}$ & $5,00 \mathrm{a}$ \\
$4,70 \%$ & $3,50 \%$ & $1,50 \%$ & $22,20 \%$ & $2,20 \%$ & $9,00 \%$ & $1,60 \%$ & $7,00 \%$ \\
\hline
\end{tabular}

Fonte: UNIWELD, 2019

\subsection{Arame tubular}

O arame tubular utilizado no revestimento superficial dos corpos de prova foi o KST TUB M 630 OA, diâmetro 1,60mm, do fornecedor KESTRA, com gás de proteção CO2 e sua composição está mostrado na Tabela 3.

Tabela 3- Composição química do arame tubular KST TUB M 630 AO

\begin{tabular}{cccc}
\hline Carbono & Silício & Cromo & Ferro \\
\hline 4,0 & 1,7 & 20,0 & Bal. \\
\hline
\end{tabular}

Fonte: KESTRA, 2015 


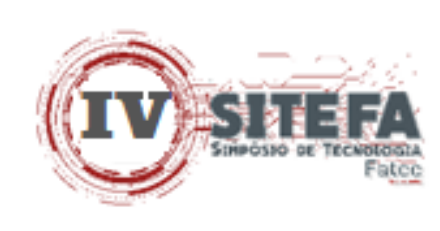

\subsection{Processo de Soldagem e Parâmetros}

A máquina de solda que foi utilizada no processo manual foi da marca Bambozzi, fonte 220 Volts. No processo semiautomático utilizou-se uma máquina da marca Miller, fonte 220 Volts. Os parâmetros de soldagem de ambos os processos estão descritos na Tabela 4. A :

Tabela 4- Parâmetros de soldagem

\begin{tabular}{ccccc}
\hline $\begin{array}{c}\text { Processo de } \\
\text { soldagem }\end{array}$ & $\begin{array}{c}\text { Diâmetro } \\
\text { (mm) }\end{array}$ & $\begin{array}{c}\text { Intensidade } \\
\text { de corrente } \\
\text { (A) }\end{array}$ & Tensão (V) & $\begin{array}{c}\text { Gás de } \\
\text { proteção }\end{array}$ \\
\hline $\begin{array}{c}\text { Eletrodo } \\
\text { revestido } \\
\text { (SMAW) }\end{array}$ & 4,00 & 140 a 180 & 24 a 28 & $\mathrm{NA}$ \\
\hline $\begin{array}{c}\text { Arame } \\
\text { tubular } \\
\text { (FCAW) }\end{array}$ & 1,60 & 180 a 240 & 24 a 28 & $\mathrm{CO}_{2}$ \\
\hline
\end{tabular}

Fonte: KESTRA, 2015

\subsection{Ensaio de metalografia}

Para realização do ensaio de metalografia, foram preparados dois corpos de prova de cada revestimento, dois revestidos com eletrodo e mais dois revestidos com arame tubular, os corpos de prova foram cortados, e preparados em lixadeira rotativa com lixas de granulometria \#80, $100,200,400,800,1000$ e 1200. Posteriormente foram polidas com óxido de cromo e com suspensão de alumina $0,3 \mu \mathrm{m}$. Após o polimento foi realizado um ataque químico nas amostras numa solução de Nital 3\% imergida durante 10s e levadas ao microscópio óptico para a análise das microestruturas, conforme norma Standard Guide for Preparation of Metallographic Specimens (ASTM E3-11). Os corpos de prova foram examinados em três tipos de captação de imagens, 50x, 100x e 200x. Estas amostras foram utilizadas para a análise metalográfica através do microscópio óptico Zeis modelo Axio Vert. A1, a fim de identificar as possíveis microestruturas formadas no metal de solda.

\subsubsection{Dureza}

As durezas dos corpos de prova foram realizadas na escala Rockwell C, com um indentador esférico com uma carga de $150 \mathrm{Kgf}$, realizada no equipamento Digital Micro Hardeness Testes MHV-2000, na temperatura de $22^{\circ} \mathrm{C}$, conforme norma Standard Test Methods for Rockwell Hardness of Metallic Materials (ASTM E18-19). Os corpos de prova utilizado no ensaio está apresentado na Figura 2. Sendo CP 01, CP 02 e CP 03, para os corpos de prova soldado com arame tubular, e CP 04, CP 05 e CP 06, para os corpos de prova soldados com eletrodo revestido. As dimensões dos corpos de prova são $25 \mathrm{~mm}$ de largura x $60 \mathrm{~mm}$ de comprimento e $12 \mathrm{~mm}$ de espessura. 


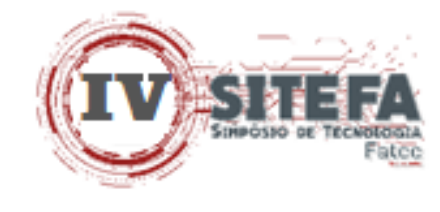

Figura 2- corpos de prova

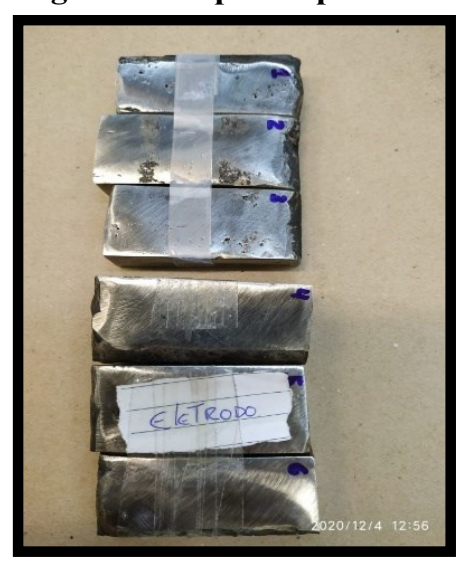

\subsubsection{Desgaste superficial}

Fonte: laboratório da FATEC (2020)

Os ensaios de abrasão superficial das amostras foram realizados no laboratório da Fatec Sertãozinho, no equipamento Abrasômetro Roda de Borracha, com areia sílica de granulometria 50/70 ASF estando dentro da exigência da norma ASTM G 65-16e1, com dimensões dos corpos de prova $60 \mathrm{~mm}$ de comprimento, $25 \mathrm{~mm}$ de largura e $12 \mathrm{~mm}$ de espessura. $O$ equipamento utilizado está representado na Figura 3.

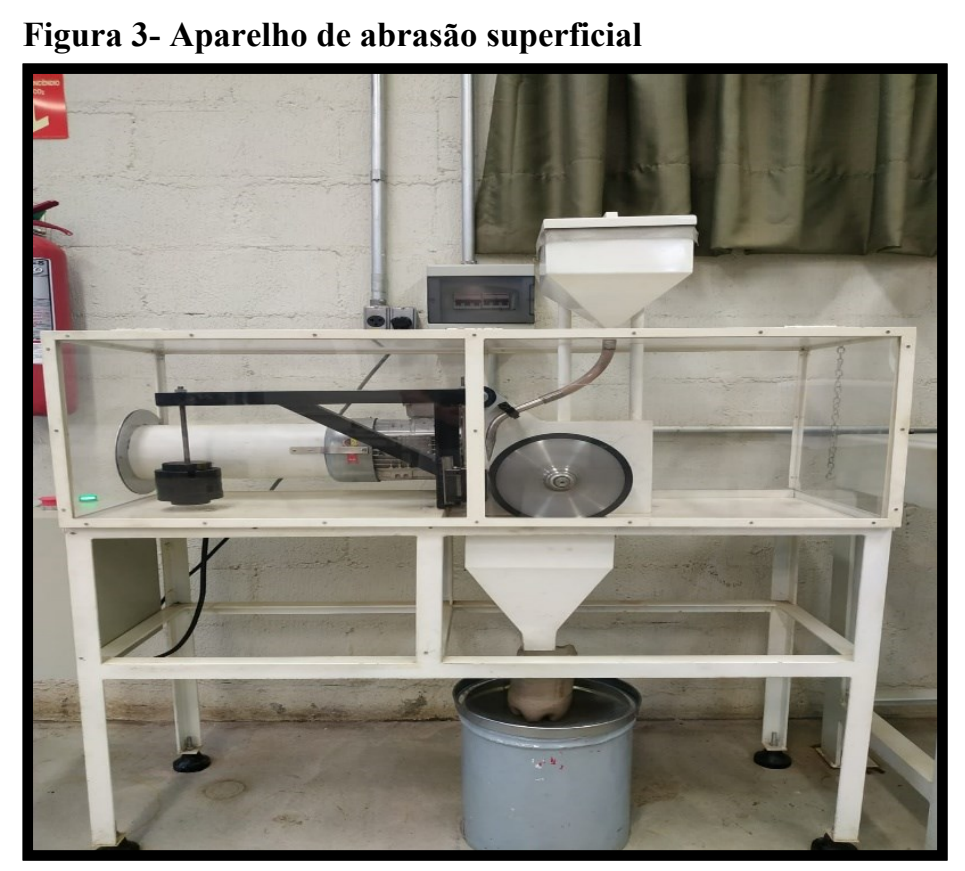

Fonte: Fatec Sertãozinho (2020)

Foi utilizado o procedimento A para a realização desse ensaio conforme a norma ASTM G65-16e1 seguindo o método abaixo:

- $\quad$ Roda de borracha, moldado sobre a superfície curva de um disco de aço com largura de $12,7 \mathrm{~mm}$ e diâmetro total de 228,6 mm, com dureza de 60 Shore A (+- 2);

- $\quad$ Rotação do disco constante de 200 RPM (+- 10 RPM); 


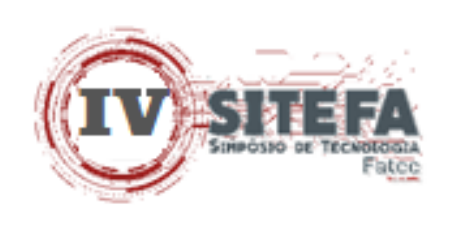

- $\quad$ Fluxo abrasivo direcionado entre a face da amostra e o disco, com vazão definida entre 300 e $400 \mathrm{~g} / \mathrm{min}$;

- $\quad$ Revoluções durante o ensaio de 100 a 6000;

- $\quad$ Carga aplicada de $130 \mathrm{~N}(+-3 \%)$; (recomendação).

Abrasivo de areia de sílica de classificação granulométrica 50/70 AFS

As amostras foram pesadas no início e no final do ensaio, utilizando uma balança com precisão de 0,001 gramas. O volume do material perdido pelas amostras ao longo do ensaio foi calculado com o resultado da diferença entre as massas final e inicial.

Para calcular a perda de volume obtidos no ensaio de desgaste foi utilizado a equação (1) da norma (ASTM G65-16e1, 2016).

Equação 1:

Perda de volume $\left(\mathrm{mm}^{3}\right)=\frac{\text { Perda de masa }(g)}{\text { Densidade }\left(\frac{g}{c^{3}}\right)} \times 1000$

Devido ao desgaste da roda de borracha durante os testes, deve-se medir o diâmetro externo da roda antes e depois do ensaio segundo a norma ASTM G65-16e1. A equação (2) é a fórmula indicada pela norma.

\section{Equação 2:}

Perda de volume corrigida $=$ Perda de volume $\times\left(\frac{227,7}{D \text { da roda depois do teste }}\right)$

\section{RESULTADOS E DISCUSSÕES}

A análise microestrutural consiste na caracterização do tipo, tamanho, forma e distribuição de fases, estruturas e impurezas presentes na deposição de solda com o uso de um microscópio, para analisar e identificar as alterações na microestrutura do material. $O$ procedimento realizado no ensaio de metalografia segundo a norma ASTM E3-11, verificou-se nos corpos de prova soldados por arame tubular (CP 01, CP 02 e CP 03) as estruturas, conforme Figura 4.

Figura 4- Corpo de prova de metalografia soldados arame tubular: a) 50x; b) 100x e c) 200x

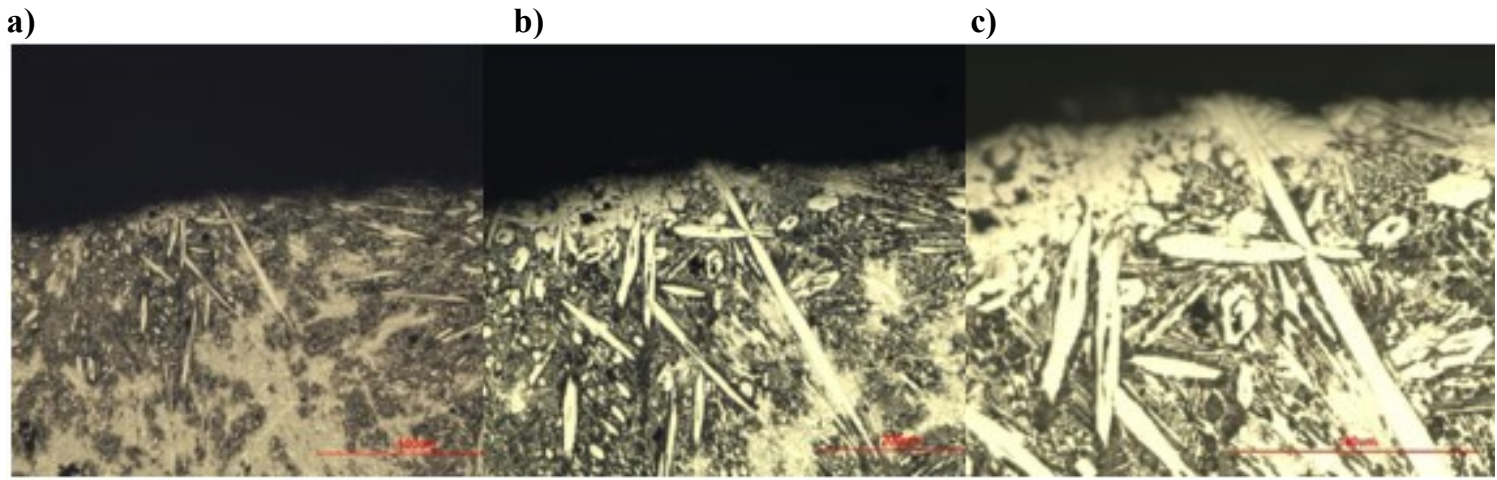

Fonte: Os autores, 2020 
O procedimento realizado no ensaio de metalografia segundo a norma ASTM E3-11, verificou-se nos corpos de prova soldados por eletrodo revestido (CP 04, CP 05 e CP 06) as estruturas, conforme Figura 5.

Figura 5- Corpo de prova de metalografia soldados eletrodo revestido: a) 50x; b) 100x e c) 200x

a)

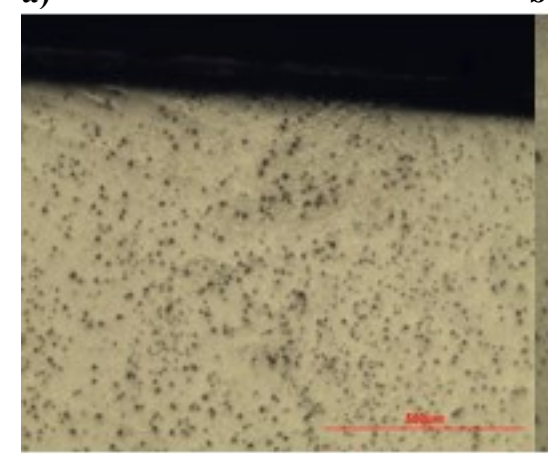

b)

Fonte: Os autores, 2020

As microestruturas presentes no deposito de arame tubular apresentam estruturas mais poligonais, típicas de estruturas martensíticas em função do teor de carbono e resfriamento rápido da poça de fusão. As microestruturas resultantes do consumível eletrodo revestido, apresentam estruturas regulares, em função do elemento molibdênio estabilizador na composição e com pontos de precipitados dispersos na matriz, semelhantes a carbonetos.

Os resultados dos ensaios de dureza estão apresentados na Tabela 5, sendo: CP 01, CP 02, CP 03 para os corpos de prova revestidos com arame tubular.

Tabela 5- Dados e resultados dos Ensaios de Dureza Rockwell C

\begin{tabular}{ccccccccc}
\hline $\begin{array}{c}\text { Identificação } \\
\text { da amostra }\end{array}$ & Escala & $\begin{array}{c}\mathbf{1}^{\mathbf{a}} \\
\text { medida }\end{array}$ & $\begin{array}{c}\mathbf{2}^{\mathbf{a}} \\
\text { medida }\end{array}$ & $\begin{array}{c}\mathbf{3}^{\mathbf{a}} \\
\text { medida }\end{array}$ & $\begin{array}{c}\mathbf{4}^{\mathbf{a}} \\
\text { medida }\end{array}$ & $\begin{array}{c}\mathbf{5}^{\mathbf{a}} \\
\text { medida }\end{array}$ & Média & $\begin{array}{c}\text { Desvio } \\
\text { Padrão }\end{array}$ \\
\hline CP 01 & HRC & 55,0 & 55,0 & 54,0 & 57,0 & 55,0 & 55,2 & 0,98 \\
\hline CP 02 & HRC & 56,5 & 56,5 & 57,0 & 55,0 & 55,5 & 56,1 & 0,73 \\
\hline CP 03 & HRC & 56,5 & 56,5 & 57,0 & 57,0 & 56,0 & 56,6 & 0,49 \\
\hline
\end{tabular}

Fonte: Os autores, 2020

Os resultados dos ensaios de dureza dos corpos de prova com eletrodo revestido estão apresentados na Tabela 6 identificados como CP 04, CP 05, CP 06.

Tabela 6- Dados e resultados dos Ensaios de Dureza Rockwell C

\begin{tabular}{ccccccccc}
$\begin{array}{c}\text { Identificaçã } \\
\text { o da }\end{array}$ & $\begin{array}{c}\text { Escal } \\
\text { amostra }\end{array}$ & $\begin{array}{c}\mathbf{1}^{\mathbf{a}} \\
\text { medid } \\
\mathbf{a}\end{array}$ & $\begin{array}{c}\mathbf{2}^{\mathbf{a}} \\
\text { medid } \\
\mathbf{a}\end{array}$ & $\begin{array}{c}\mathbf{3}^{\mathbf{a}} \\
\text { medid } \\
\mathbf{a}\end{array}$ & $\begin{array}{c}\mathbf{4}^{\mathbf{a}} \\
\text { medid } \\
\mathbf{a}\end{array}$ & $\begin{array}{c}\mathbf{5}^{\mathbf{a}} \\
\text { medid } \\
\mathbf{a}\end{array}$ & $\begin{array}{c}\text { Médi } \\
\mathbf{a}\end{array}$ & $\begin{array}{c}\text { Desvio } \\
\text { Padrã }\end{array}$ \\
\hline CP 04 & HRC & 53,0 & 51,0 & 50,0 & 53,0 & 52,0 & 51,8 & 1,17 \\
\hline CP 05 & HRC & 54,0 & 53,0 & 55,0 & 55,0 & 53,0 & 54,0 & 0,89 \\
\hline CP 06 & HRC & 52,5 & 55,0 & 53,0 & 53,0 & 54,0 & 53,5 & 0,89 \\
\hline
\end{tabular}

Fonte: Os autores, 2020

Os resultados de dureza do deposito de solda esperado para o arame tubular conforme fabricante é de 58 a $62 \mathrm{HRC}$, porém o resultado obtido de dureza ficou um pouco abaixo. Para 
o consumível eletrodo revestido a dureza esperada, conforme fabricante é na faixa de 57 a 62 $\mathrm{HRC}$, onde se obteve um valor mais baixo no depósito. Ambos os processos, as durezas encontradas no deposito de solda ficaram próximos, abaixo do especificado pelo fabricante onde a diferença dos valores foi um pouco maior para o processo arame tubular, em função da estrutura irregular e poligonal conforme mostrado na Figura 4. Os resultados do ensaio por roda de borracha segundo a norma ASTM G65-16e1 está apresentado na Tabela 7 para os corpos de prova do processo arame tubular.

Tabela 7- Dados de resultados do ensaio por roda de borracha

\begin{tabular}{lllllll}
\hline $\begin{array}{l}\text { Identificação } \\
\text { da Amostra }\end{array}$ & $\begin{array}{l}\text { Massa } \\
\text { Inicial }\left(\mathbf{m}_{\mathbf{0}}\right)\end{array}$ & $\begin{array}{l}\text { Massa Final } \\
\left(\mathbf{m}_{\mathbf{f}}\right)\end{array}$ & $\Delta \mathbf{m} \mathbf{( m g )}$ & $\begin{array}{l}\text { Perda } \\
\text { volume } \\
\mathbf{m m}^{\mathbf{3}} \mathbf{)}\end{array}$ & $\begin{array}{l}\text { de } \\
\begin{array}{l}\text { Perda } \\
\text { volume } \\
\text { corrigida } \\
\left(\mathbf{m m}^{\mathbf{3}}\right)\end{array}\end{array}$ \\
\hline CP 01 & 142,0029 & 141,9704 & 0,0325 & 4,1275 & 4,1349 \\
\hline CP 02 & 155,83356 & 155,8192 & 0,01436 & 1,8237 & 1,8269 \\
\hline CP 03 & 139,2645 & 139,2473 & 0,0172 & 2,1844 & 2,1883 \\
\hline
\end{tabular}

Fonte: Os autores, 2020

Os resultados do ensaio por roda de borracha segundo a norma ASTM G65-16e1 está apresentado na Tabela 8 para os corpos de prova do processo eletrodo revestido.

Tabela 8- Dados de resultados do ensaio por roda de borracha

\begin{tabular}{|c|c|c|c|c|c|c|}
\hline $\begin{array}{l}\text { Identificação } \\
\text { da Amostra }\end{array}$ & $\begin{array}{l}\text { Massa } \\
\text { Inicial }\left(\mathrm{m}_{\mathrm{o}}\right)\end{array}$ & $\begin{array}{l}\text { Massa Final } \\
\left(\mathbf{m}_{\mathrm{f}}\right)\end{array}$ & $\Delta \mathbf{m}(\mathrm{mg})$ & $\begin{array}{l}\text { Perda } \\
\text { volume } \\
\left(\mathrm{mm}^{3}\right)\end{array}$ & de & $\begin{array}{l}\text { Perda de } \\
\text { volume } \\
\text { corrigida } \\
\left(\mathrm{mm}^{3}\right)\end{array}$ \\
\hline CP 04 & 185,0419 & 185,0315 & 0,0104 & 1,3208 & & 1,3231 \\
\hline CP 05 & 177,1977 & 177,1837 & 0,014 & 1,7780 & & 1,7812 \\
\hline CP 06 & 166,8637 & 166,8505 & 0,0132 & 1,6764 & & 1,6794 \\
\hline
\end{tabular}

Fonte: Os autores, 2020

Os resultados de desgaste dos CPs de arame tubular mostraram um desgaste maior que os do revestimento com eletrodo revestido. Este resultado pode ser devido as estruturas encontradas no deposito de solda, corroborando com a sua dureza. A condição diferente do deposito de solda na forma regular e de precipitados apresentados no deposito de eletrodo revestido, proporcionaram uma melhor relação de aplicação ao desgaste.

\section{CONCLUSÃO}

Os resultados do ensaio de metalografia e dureza, indicam que os corpos de prova soldado com arame tubular apresentaram melhores resultados em função dos precipitados de cromo disperso na matriz, porém no ensaio de desgaste o mesmo apresentou uma maior perca de volume devido a forma irregular e poligonal da estrutura resultante no deposito de solda, diferente condição encontrada no depósito de eletrodo revestido que indicam uma dispersão de precipitados homogêneas proporcionando resultados de dureza satisfatórios com a estrutura analisada. Contudo o desgaste foi menos severo neste revestimento, com menor perda de volume. 


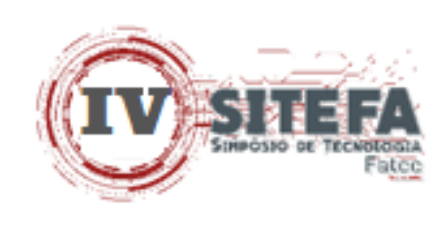

Sendo assim, uma faca picadora de cana de açúcar em operação de trabalho, o fator de desgaste é mais relevante devido ela estar girando em altas rotações em contato com a cana de açúcar e as impurezas e pelos resultados obtidos, a soldagem com o eletrodo revestido é o mais indicado para se realizar o revestimento da superfície.

\section{REFERÊNCIAS}

ALLGAYER, A.A. Caracterização das propriedades mecânicas e metalúrgicas de uma junta de aço ASTM A36 soldado pelo processo de arco submerso com diferentes aportes térmicos. Lajeado: Centro Universitário Univates, junho de 2017. Disponível em: https://www.univates.br/bdu/bitstream/10737/1667/1/2017AlexandreAndreAllgayer.PDF / Acesso em: 02 out. 2020.

AMERICAN SOCIETY FOR TESTING AND MATERIALS (ASTM). ASTM E18- 19. Standard methods for Rockwell hardness and Rockwell superficial hardness of metallic materials. ASTM International, USA, 2019.

American Society for Testing and Materials. ASTM G65-16e1, Standard Test Method for Measuring Abrasion Using the Dry Sand/Rubber Wheel Apparatus. ASTM International, USA, 2016.

American Society for Testing and Materials. ASTM E3-11, Standard Guide for Preparation of Metallografic Specimens. ASTM International, USA, Dec. 2011.

ASTM A36 / 36M. Standard Specification for Carbon Structural Steel: Annual Book of ASTM Standards. USA: [s.n.]. 2008. 4p

CALLISTER Jr., W. D.; RETHWISCH D. G.. Ciência e Engenharia de Materiais - uma introdução. Editora LTC, 10 Edição. 2020.

FORTES, C.. Catálogo Arame Tubular, Esab BR, 2004, Disponível em:

https://www.esab.com.br/br/pt/education/apostilas/upload/1901098rev1_apostilaaramestubula res_ok.pdf. Acesso em: 03 jun. 2020.

KESTRA. Kestra Consumíveis de Soldagem. Norma DIN 8555 MF 10-60-GR, 2015. Disponível em: kestra.com.br. Acesso em: 10 set. 2020.

LIMA, A. C.; FERRARESI, V. A. Desgaste em Equipamentos de Processamento da Cana de Açucar em Destilaria de Álcool. $16^{\circ}$ POSMEC, Simpósio de Pós-Graduação em Engenharia Mecânica FEMEC/UFU, Uberlândia-MG, 2006. Disponível em: https://www.agencia.cnptia.embrapa.br/Repositorio/PM160092_000fxg23qv402wyiv80soht9 hrcsev2d.pdf. Acesso em: 15 mar. 2020.

LIMA, A. C. et al.. Soldagem de Revestimentos Duros em Facas Picadoras de Cana-deAçúcar de Indústria Sucroalcooleira: eletrodo revestido "versus" arame tubular. Goiânia: Instituto Federal de Educação, Ciência e Tecnologia de Goiás. IFG, 2012. 


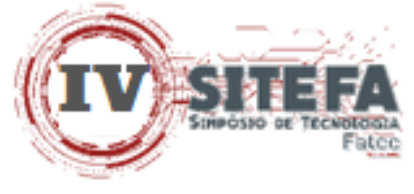

Disponível em: http://propi.ifto.edu.br/ocs/index.php/connepi/vii/paper/viewFile/1969/2455. Acesso em: 19 jun. 2020.

LUZZI, B. F.; OKURA, H. N. Análise da resistência ao desgaste de revestimentos Intermetálicos Fe-Al usando ensaio de roda de borracha. 2012. $96 \mathrm{f}$. Trabalho de Conclusão de Curso (Graduação) - Universidade Tecnológica Federal do Paraná, Curitiba, 2012.Disponível em: http://repositorio.roca.utfpr.edu.br/jspui/handle/1/6154. Acesso em: 15 mar. 2020.

LUZ, G. Ensaio de Dureza. Blog Materiais, [s. 1], 2017. Disponível em: https://www.materiais.gelsonluz.com/2017/10/ensaio-de-dureza.html. Acesso em: 14 jul. 2020.

MARQUES, P.; MODENESI, P.; BRACARENSE, A.. Soldagem: fundamentos e tecnologia. 3 ed. Belo Horizonte: Editora UFMG, 2011.

MILAN, M. et al. Metais: uma visão objetiva. ed. São Carlos: Editora Cubo, 2014.

MODENESI, P.; MARQUES, P.; SANTOS, D.. Introdução a Metalurgia da Soldagem. Belo Horizonte: Universidade Federal de Minas Gerais, janeiro de 2012. Disponível em: https://demet.eng.ufmg.br/wp-content/uploads/2012/10/metalurgia.pdf. Acesso em 13 jun. 2020.

SOLBRINIL. Solbrinil Equipamentos e Serviços Industriais. Catálogo, setembro de 2020. Disponível em: http://www.solbrinil.com.br/facas-picador-cana / Acesso em: 15 set. 2020.

UNIÃO DA INDÚSTRIA DE CANA-DE-AÇÚCAR (ÚNICA). Disponível em http://www.unica.com.br. Acesso em: 02 fev.2020.

UNIWELD INDÚSTRIA DE ELETRODO (UNIWELD). ESSEN CCR 65. Produto Especial. Disponível em: http://www.uniweld.com.br/wp-content/uploads/2020/01/FichaT\%C3\%A9cnica-Essen-CCR-65-PRODUTO-ESPECIAL.pdf (2019). Acesso em: 10 set. 2020 . 